\title{
Truth is Stranger than Science Fiction: The Quest for Knowledge in Andrei Tarkovskii's Solaris and Stalker
}

\author{
THOMAS MCLENACHAN \\ School of Slavonic and East European Studies
}

This article explores Andrei Tarkovskii's conception of truth in Solaris (1972) and Stalker (1979) as part of his wider philosophical project concerning knowledge. The director's epistemological views form a core dimension of his life and aesthetic as he strives towards what he considers a higher, spiritual 'idea of knowing'. In his search for this idealised notion of truth, Tarkovskii uses the medium of film to address what he perceives as a profound imbalance in modern civilization between scientific rationalism and spiritual/aesthetic 'truth'. This is nowhere more prominent than in his two science fiction films, Solaris and Stalker, as he uses the genre as a battleground to discuss key debates in epistemology. Comparisons will be made with the Russian author and thinker Tarkovskii most revered, Fyodor Dostoevskii, and the Soviet-period science fiction authors whose works he adapted, Stanisław Lem and the Strugatskii brothers, in order to elucidate how the director came to cinematically represent his philosophy.

\section{INTRODUCTION}

In his written manifesto, Sculpting in Time (1987), Andrei Tarkovskii begins to map out his ideas about truth and knowledge, which are central to his philosophy and permeate his films. As he attempts to distinguish truth from falsehood, he marks out two opposing forms of knowledge: scientific and aesthetic. ${ }^{1}$ The former is based on a positivist rationale that tries to amass objective knowledge of the outside world, while the latter arrives at the truth through a subjective understanding of the inner self. In his written works and films, Tarkovskii is explicit that he prioritises the latter, an aesthetic form of knowledge, over any scientific approaches to the truth. However, the intricacies of this are not so straightforward:

\footnotetext{
${ }^{1}$ Andrei Tarkovskii, Sculpting in Time (London: Faber and Faber, 1987), p. 37 (hereafter: 'Tarkovskii, Sculpting in Time'). It is important to note that, while published in 1987, Tarkovskii began writing Sculpting in Time at least fifteen years before, demonstrating that his philosophical views were consistent at least throughout the second half of his career.
} 
To start with the most general consideration, it is worth saying that the indisputably functional role of art lies in the idea of knowing, where the effect is expressed as a shock, as catharsis. From the very moment when Eve ate the apple from the tree of knowledge, mankind was doomed to strive endlessly after the truth. First, as we know, Adam and Eve were discovered naked. And they were ashamed. They were ashamed because they understood; and then they set out on their way in the joy of knowing one another. That was the beginning of a journey that has no end. ${ }^{2}$

Many scholars and critics of Tarkovskii's works have reached the conclusion that his films are hinged on a central conflict between two separate worlds: the external and the internal. ${ }^{3}$ The former is dominated by the material or physical universe and the latter by individual consciousness, spirituality, and memory. The existing literature, however, ignores how these worlds are intrinsically linked to Tarkovskii's ideas about knowledge and truth. He posits science, his first form of 'knowing', as a reductionist way of understanding the "external" world through its objectification and law building. ${ }^{4}$ While Tarkovskii does not wholly reject a rational approach to knowledge, his idealised truth is conceived "internally" in the subjective and poetic mind of the individual. ${ }^{5}$ Accordingly, these two branches of knowledge do not grow from the same root but are instead at variance with each other precisely because they are informed by our experience of the two separate worlds: the external and the internal. In his films, Tarkovskii creates an abstract dialogue between these two worlds, asking a series of questions: What is knowledge? How is knowledge acquired? What "forms" of knowledge are most important to the human experience? This article will bring such questions of epistemology to the forefront of analysis in order to understand this central conflict in Tarkovskii's works.

It is, of course, necessary to immediately question the rationality behind any attempt to contrast different types of knowledge. Arguably, there is no viable way to

\footnotetext{
${ }^{2}$ Tarkovskii, Sculpting in Time, p. 37. The Russian language has two significantly different words for truth: pravda and istina. The term pravda usually denotes an observable truth, often associated with social justice, whereas istina evokes a higher, absolute truth. Tarkovskii's truth is unmistakably istina, as indicated by the epigraph of this work: 'beskonechnoe stremlenie k istine'.

${ }^{3}$ See Vida T. Johnston and Graham Petrie, The Films of Andrei Tarkovskii: A Visual Fugue (Bloomington, IN: Indiana University Press, 1997), p. 231 (hereafter: 'Johnson and Petrie, A Visual Fugue'); Simonetta Salvestroni, 'The Science-Fiction Films of Andrei Tarkovsky', Science Fiction Studies, 14:3 (Nov., 1987), pp. 294-306 (p. 294); and Mark Le Fanu, The Cinema of Andrei Tarkovskii (London: British Film Institute, 1987), p. 102.

${ }^{4}$ Tarkovskii, Sculpting in Time, p. 37.

${ }^{5}$ Ibid.
}

(c) School of Slavonic and East European Studies, University College London, 2014. 
compare scientific and aesthetic 'truth', or indeed arrange them in an epistemic hierarchy. Only science deals with observable, testable truths that can be validated or disproven. Similarly, Tarkovskii's idea of aesthetic truth could well represent a higher, absolute Truth, yet it is both irrefutable and indefensible. Here lies one of the several fundamental problems in Tarkovskii's attempt to rebalance materialism and spirituality, which will be addressed in greater detail later in this article. However, as Tarkovskii at times resorts to evaluating the categories of 'scientific truth' and 'aesthetic truth' alongside each other, this paper will explore them in a similar manner in an attempt to improve our understanding of his philosophy. To test the proposed hypothesis for Tarkovskii's conceptualisation of truth, this paper is split into two parts, discussing the role of truth in relation to science and art respectively. The first section, 'Truth in Science', focuses on Tarkovskii's representation of science, scientists, and scientific truths. The initial discussion will shed light on Tarkovskii's attempt to subvert the science fiction genre in Solaris and Stalker by removing the scientific aspects of the novels in favour of a more natural setting.

Following this, the analysis will move on to Tarkovskii's handling of the metaphysical question concerning the alien Other and the limits of human understanding. Of primary concern will be the changes Tarkovskii makes in adapting the original novels on which the films are based, Stanisław Lem's Solaris $(1961)^{6}$ and the Strugatskii brothers' Roadside Picnic $(1972)^{7}$, so that the integral questions regarding knowledge are slanted in favour of his own ideological 'truths'. Recognition of these changes makes it possible to differentiate between the epistemological posturing of Tarkovskii and the science fiction authors. This is supplemented by an exploration of the subtle differences that divide Lem and the Strugatskii brothers, which provides insight into the representation of knowledge in the Soviet-period science fiction literature during the 1960s and 1970s.

The second section, 'Truth in Art', presents a more conceptual discussion, as due to a number of complicating factors Tarkovskii's idea of aesthetic truth is more

\footnotetext{
${ }^{6}$ Stanisław Lem, Solaris (New York: Mariner Books, 2002) (originally published in 1961; hereafter: 'Lem, Solaris').

${ }^{7}$ Arkadii Strugatskii and Boris Strugatskii, Roadside Picnic (London: V. Gollancz, 1978) (originally published in 1972; hereafter: 'Strugatskii, Roadside Picnic').
}

(c) School of Slavonic and East European Studies, University College London, 2014. 
difficult to define. First, aesthetic truth is, by definition, a more abstract and nonrational way of 'knowing'. Second, Tarkovskii often uses the terms 'aesthetic truth' and 'spiritual truth' interchangeably. ${ }^{8}$ Attempts to distinguish between the aesthetic and the spiritual are further undermined by the fact that Tarkovskii tends to illustrate them both through negation. Most often, he quantifies them through the questioning of the superiority of scientific knowledge rather than by discussing their attributes and intricacies. The conclusion will attempt to resolve these issues, making an assessment of Tarkovskii's attempt to rebalance the so-called forms of knowledge and the consistency with which he applies his philosophy to the two films in question. Reference will be made throughout to Sculpting in Time which, with the exception of Robert Bird's Andrei Tarkovsky: Elements of Cinema9, has been largely overlooked as a philosophical text.

\section{Truth in Science}

\section{Anti-Science Fiction: Tarkovskii and Genre}

Science fiction has always been an arena of unusual stylistic oppositions and experimentations. Tarkovskii's metamorphosis of Solaris and Roadside Picnic, however, goes beyond the generic boundaries of sci-fi, adding new conflict to this existing tension. The adaptation process from the original novels involved a constant struggle between the director and the genre. Tarkovskii tried to disengage from the conventions of science fiction as much as possible, stating that he was 'no more interested, in the fantastic plot of Stalker than [he] had been in the sci-fi story-line of Solaris' ${ }^{10}$ It has been suggested that Tarkovskii merely chose the genre as an act of expediency rather than for its artistic value. ${ }^{11}$ Yet, science fiction, especially the works of Lem and the Strugatskii brothers, had an extensive readership in the Soviet

\footnotetext{
${ }^{8}$ Tarkovskii, Sculpting in Time, p. 37. It is possible to argue that, rather than being a subordinate part of his aesthetic truth, spiritual or religious knowledge constitutes an autonomous third branch in Tarkovskii's epistemic hierarchy. It would be desirable to explore this further, adding a third section to this article, however space precludes this.

${ }^{9}$ Robert Bird, Andrei Tarkovsky: Elements of Cinema (Reaktion Books, 2008).

${ }^{10}$ Tarkovskii, Sculpting in Time, p. 199.

${ }^{11}$ O Tarkovskom ['About Tarkovskii'], ed. by Marina Tarkovskaya (Moscow: Progress Publishers, 1989), p. 166.
}

(c) School of Slavonic and East European Studies, University College London, 2014. 
Union and was more likely to be commissioned by the central film-body Goskino than Tarkovskii's other desired projects. ${ }^{12}$ Regardless of his motives, Tarkovskii considered the existing works by Lem and the Strugatskii brothers as mere raw material that allowed for a radical reshaping of its content. Stalker, in particular, bears little resemblance to the original novel Roadside Picnic. Tarkovskii consciously manipulates the genre, reversing many of its key characteristics in order to convey his critique on knowledge.

One key change that Tarkovskii makes is the minimisation of the technological fetishism commonly associated with science fiction. For Solaris, he shunned what he called an 'exoticism of technology' because 'a detailed "examination" of the technological process of the future transforms the emotional foundations of a film, as a work of art, into a lifeless schema with only pretensions to the truth'. ${ }^{13}$ This steadfast viewpoint is especially interesting considering that the role of technology in Lem's novels is already relatively subtle in comparison to the contemporaneous 'hard' Soviet science fiction by Ivan Yefremov, Mikhail Yemtsev, and others. Surprisingly, the initial literary script that Tarkovskii submitted for Solaris actually 'introduced additional sf elements in the script: a transparent film which covers a park, children moving by jet-propelled belts, and a 204-floor building where Kris lives' ${ }^{14}$ Again, it must be presumed that these were temporary measures to satisfy the commissioning board at Goskino. In a complete turn of events, the minutes from a studio discussion stored in the Mosfilm archives reveal that Tarkovskii later expressed a desire for the entire film to be set on Earth, much to the dismay of Lem who was actively involved in the adaptation process. ${ }^{15} \mathrm{~A}$ compromise was reached whereby a considerable part of the action took place on Earth and the scenes in space were shot on a relatively minimalist set in Mosfilm studios, making it an unmistakably terrestrial experience throughout. In the film, Tarkovskii preferred a more modest use of 'lifeless' gadgetry in favour of earthly

\footnotetext{
${ }^{12}$ For example, Tarkovskii had several failed attempts to secure funding for an autobiographical film before eventually making his seminal work The Mirror in 1975.

${ }^{13}$ Andrei Tarkovsky Interviews, ed. by John Gianvito (Jackson, MI: University Press of Mississippi, 2006),

p. 36 (hereafter: 'Gianvito, Interviews').

${ }^{14}$ Ibid.

${ }^{15}$ See Andrei Tarkovskii, Collected Screenplays (London: Faber and Faber, 1999), p. 130 (hereafter: 'Tarkovskii, Screenplays').
} 
objects as evidenced by the space station Solaris being adorned with plants, wooden furniture and fittings, and works of earth-themed art. ${ }^{16}$ Despite technology being a prominent feature of the novel, the only remotely futuristic element of Solaris is a sequence filmed in Tokyo which sees the character Berton looking lifelessly into the camera as he drives around the modernised Japanese metropolis. This four-minute segment, partly filmed in black and white, does not feature any dialogue, nor does it develop the plot in a meaningful way. It is possible to assert, therefore, that the minimal use of such "scientific" elements in Solaris was designed partly to satisfy studio commission panels and, more importantly, to function as a reminder of Tarkovskii's warning against the encroachment of science and materialism on modern civilization. Nonetheless, Tarkovskii concedes that there were 'too many pseudo-scientific gadgets in the film' and that ' $[\mathrm{m}]$ odern man is too preoccupied by his material development, by the pragmatic side of reality' ${ }^{17}$

As he attempts to humanise the genre by removing technology and adding natural 'truths', he creates something more akin to anti-science fiction that is representative of his own distinctive philosophy. The director believed that man is essentially a spiritual being who needs to conquer the natural realm before the technological. He stated that he preferred to be 'away from the paraphernalia of modern civilization' in a more natural setting such as his dacha where 'rain, fire, water, snow, dew, the driving ground wind - are all part of the material setting of which we dwell; I would even say of the truth of our lives'. ${ }^{18}$ This sentiment is reflected in the opening of Solaris: the camera closely studies the earth, filming at root level the tranquil, pastoral world, painted by flowing water reeds and the Tarkovskian trope of the dacha. These shots immediately establish a close intimacy with nature, contrasting with the sterile setting of the space station.

Stalker marked an even more comprehensive removal of all technology and space-based landscapes in favour of a more natural setting. Evidence from the original drafts of the script, of which there were thirteen in total, show that the process of removing the scientific and technological elements from Roadside Picnic

\footnotetext{
16 Ibid.

${ }^{17}$ Gianvito, Interviews, p. 173.

${ }^{18}$ Tarkovskii, Sculpting in Time, p. 212 [my emphasis].
} 
was gradual and conscious. ${ }^{19}$ The same feeling of intimacy with nature is created in the opening sequences of Stalker when the eponymous protagonist returns to the Zone and amorously embraces the soil while worms and insects crawl over his skin. Once again, the lusciousness of the Zone, with its pulsating green grass and overgrown passageways, is contrasted against the preceding monochrome images of the industrialised, man-made world. The overwhelming impression here is that nature carries with it a sensation of truth in Tarkovskii's world. In his 'conflict between spirit and matter', nature is the one constant in the material realm that holds true..$^{20}$ Tarkovskii, like his central characters, tries to get as close to nature as possible, both in the physical and spiritual sense but, importantly, he does so without attempting to understand it scientifically as 'the pathos of human existence doesn't lie in comprehension'. ${ }^{21}$ The closer his characters get to nature, the further they distance themselves from science, and the more morally aware they become. For Tarkovskii, the advance of technology and materialism meant that man was distracted from deep, spiritual truths which occur in the natural world. In his eyes, science is limiting because it perceives the natural world as a morally neutral object, an impartial entity waiting to be understood by man in a systematic rather than an existential manner. In this respect, Tarkovskii represents science as an objectivising force that has the potential to sidetrack expansive, subjective understanding of the human condition.

Tarkovskii laments that ' $[\mathrm{i}] \mathrm{n}$ our attempt to protect ourselves from nature and to conquer it, we have given so much preference to our material development that we've ended up quite unprepared to cope with this technology we have created'.22 There is a slight irony in Tarkovskii's criticism of modernisation here as his chosen art form, film, inherently depends on the very technological advances that he brings into question. Unlike his idealised canon of nineteenth-century authors, Tarkovskii's journey in art requires not only a mastering of the aesthetic but also of the technical. Slavoj Žižek, in his characteristically provocative fashion, goes as far as to claim that

\footnotetext{
${ }^{19}$ See Tarkovskii, Screenplays.

${ }^{20}$ Gianvito, Interviews, p. 94.

${ }^{21}$ Ibid., p. 115.

${ }^{22}$ Gianvito, Interviews, p. 94.
}

(c) School of Slavonic and East European Studies, University College London, 2014. 
'Tarkovskii's cinematic texture undermines his own explicit ideological project'. ${ }^{23}$ This, however, is an exaggeration of reality, as the director intended to merely question the superiority of science and materialism, rather than reject them outright. The changes that he makes in adaptations represent scientific truth as being a limited yet necessary approach to knowledge that must be balanced against natural, spiritual truths. Nonetheless, the director seems to overlook the possibility of science and art as having different, yet ultimately equal paths to understanding truth in nature.

\section{The Final Frontier of Knowing}

A central issue of epistemological debate is the hypothetical limit of human knowledge. ${ }^{24}$ In science fiction, this is often represented by extraterrestrial life and man's ability, or inability, to envisage extraterrestrial life-forms. This is one of Lem's primary concerns with Solaris in which he explores the significance of reaching this symbolic boundary. ${ }^{25}$ In the novel, the alien-planet Solaris acts as a metaphor for the insurmountable peak of human knowledge. Despite centuries of study, scientists are unable to establish any facts or scientific certainties about this mystery. The work of Solaristics, the branch of science dedicated to studying Solaris, ultimately 'represents a body of incommunicable knowledge. Transposed into any human language, the values and meanings involved lose all substance; they cannot be brought intact through the barrier' ${ }^{26}$ Lem's scientists are forever burdened by their incapacity to think outside of the so-called human language and overcome the anthropomorphism inherent in scientific thought. This is apparent when Kris attempts to describe the alien-planet but feels constrained by human vocabulary: 'The free-ranging forms [of Solaris] are often reminiscent of many-winged birds, darting away from the moving trunks of the agilus, but preconceptions of Earth offer

\footnotetext{
23 Slavoj Žižek, 'The Thing from Inner Space', in Sexuation, ed. by Salecl Renata (Durham, NC: Duke University Press, 2000), pp. 216-259 (p. 242).

${ }^{24}$ For a recent evaluation of this debate see Timothy Williamson, Knowledge and its Limits (Oxford: Oxford University Press, 2002); David Papineau, Philosophical Devices: Proofs, Probabilities, Possibilities, and Sets (Oxford: Oxford University Press, 2012).

${ }^{25}$ Istvan Csicsery-Ronay Jr, 'The Book Is the Alien: On Certain and Uncertain Readings of Lem's "Solaris", Science Fiction Studies, 12:1 (Mar., 1985), pp. 6-21 (p. 7).

${ }^{26}$ Lem, Solaris, p. 172.
} 
no assistance in unravelling the mysteries of Solaris' ${ }^{27}$ Critically for Lem, the inescapability of man's capacity to comprehend the universe only in human terms is his great failing. For Tarkovskii, however, this is not a limitation but a distraction. Tarkovskii believes, man's preoccupation with the hypothetical knowledge barrier is itself the problem rather than the barrier. This epistemological shift is reflected in the dialogue:

Bureaucrat 1: All we know about Solaris reminds me of a mountain of separate facts which we are unable to squeeze into a framework of any conception.

Kelvin: Well, we're even worse off today, as regards to the essential. Solaristics is degenerating.

Bureaucrat 2: The essential question is far more serious than just Solaristics. We're probing the very frontier of human knowledge. By artificially establishing a knowledge frontier, we limit our concept of the infinity of man's knowledge. And if our movement is not forward, do we not risk moving backward?28

In Tarkovskii's film, the planet Solaris retains symbolic value, yet he portrays attempts to understand it as mere detraction from more important issues affecting the human condition such as art and spirituality. This view was reasserted in an interview with Thomas Johnson in 1986, in which he exclaims ' $[w]$ hat good is it to go out into space if it's only to distance ourselves from the fundamental problems of man: the harmonising of the spiritual and the material world?' ${ }^{29}$ Tarkovskii believed that a complete understanding of the self is a vital prerequisite to understanding the alien Other. Therefore, in order to shift the epistemological focus, Tarkovskii greatly reduces the significance of the alien-planet Solaris. While large sections of the novel are dedicated to describing Solaris and Solaristics, in the film they are merged into a larger analogy of the scientific method as a whole.

\footnotetext{
${ }^{27}$ Ibid., p. 123.

28 Soliaris ['Solaris'], dir. by Andrei Tarkovskii (Mosfil’m, 1972) [English subtitles] (hereafter: Solaris, Tarkovskii).

${ }^{29}$ Ibid., p. 174.
}

(c) School of Slavonic and East European Studies, University College London, 2014. 
For Tarkovskii, science is often a synthetic process that simply gathers objective truths and uses them to strengthen the "barrier" of scientific knowledge. In Sculpting in Time, he introduces a metaphor of an endless staircase to describe this:

In science, man's knowledge of the world makes it up an endless staircase and is successively replaced by new knowledge, with one discovery often being disproved by the next for the sake of a particular objective truth. An artistic discovery occurs each time as a new and unique image of the world, a hieroglyphic of absolute truth. ${ }^{30}$

Tarkovskii's representation of science here is highly reminiscent of Dostoevskii's satirical parody, Notes from the Underground (1864). ${ }^{31}$ In the novel, the unnamed narrator, generally referred to as the Underground Man, gives an impassioned critique on science and Western rationalism. He warns the reader about the limitations of scientific thought, which he represents with a metaphor of a 'stone wall':

What stone wall? Why, of course, the laws of nature, the deductions of natural science, mathematics. As soon as they prove to you, for instance, that you are descended from a monkey, then it is no use scowling, accept it for a fact $[\ldots]$ for $2+2=4$ is a law of mathematics. Just try refuting it. ${ }^{32}$

Dostoevskii's Underground Man is fascinated by what is beyond the wall but he is only able to glimpse over the top. The metaphorical wall becomes higher as each new brick, representing a new scientific law or 'truth', is placed on top. The higher it climbs, the tighter science's grip on the truth becomes, making it harder to scale. The attempts of the Underground Man to break through the wall with his forehead are futile. He is a holder of a 'higher and deeper' form of knowledge, akin to Tarkovskii's spiritual form of knowing, yet he is unable to refute the laws of science or mathematics in any kind of rational way. ${ }^{33}$ Ultimately, the Underground Man declares 'wall building' a reductive act and attempts to find the truth within himself rather than in the bricks. ${ }^{34} \mathrm{He}$ concludes that '[c]onsciousness is infinitely higher

\footnotetext{
30 Tarkovskii, Sculpting in Time, p. 37.

31 Fyodor Dostoevskii, Notes from the Underground (London: Bloomsbury Academic, 1998) (originally published in 1864; hereafter: 'Dostoevskii, Notes from the Underground').

${ }^{32}$ Dostoevskii, Notes from the Underground', p. 13.

${ }^{33}$ Ibid.

${ }^{34}$ Ibid.
}

(c) School of Slavonic and East European Studies, University College London, 2014. 
than $2+2=4[\ldots]$ after all, $2+2=5$ is not without its attractions' ${ }^{35}$ Tarkovskii would later make reference to this in his penultimate film Nostalgia (1983) 36 in which one of his key heroes Domenico - holder of his higher, spiritual knowledge - writes the sum ' $1+1=1$ ' on the wall and proclaims that 'one plus one does not equal two but a bigger one!'. 37 Tarkovskii writes in his diary on 13 April 1986 that such equations cannot be true 'because there can be no such thing as positive knowledge'. ${ }^{38}$ These words are echoed by the Writer in Stalker who laments that:

The world is ruled by cast-iron laws, and it's insufferably boring. Alas those laws are never violated. They don't know how to be violated...There is no Bermuda Triangle. There's only Triangle ABC that equals Triangle A-prim, B-prim, C-prim. Do you feel the boredom contained in this assertion? ${ }^{39}$

The intention of both Tarkovskii and Dostoevskii here is to represent scientific truths as being inherently limited in comparison to more expansive spiritual or aesthetic truths which are not confined by rationalism. Their alternatives sums of ' $2+2=5$ ' and ' $1+1=1$ ' defy mathematical reasoning and are designed to destabilise scientific logic. Importantly, both suggest that there is more truth to be found in the irrationality of poetic logic than in the predictability of science.

Aside from his reworking of the "knowledge barrier" in Solaris, a second key change that allows Tarkovskii to demote scientific knowledge whilst bringing spiritual values to the forefront is his modification of Lem's psi-creatures. In the novel and the film, the scientists are haunted by mysterious psi-creatures or phantoms which take on human form and walk freely around the space station. At first, the scientists believe them to be hallucinations before coming to realise that the alien-planet Solaris is producing them from their unconscious memory. They begin to feel affection for the psi-creatures, in full knowledge that they are not real, at least in the human sense of the word. At this point the novel and the film take

\footnotetext{
${ }^{35}$ Ibid., p. 19.

${ }^{36}$ Nostalgiia ['Nostalgia'], dir. by Andrei Tarkovskii (Mosfil 'm, 1983) [English subtitles].

${ }^{37}$ Andrei Tarkovskii, Time within Time: the Diaries 1970-86 (London: Faber and Faber, 1994), p. 374.

${ }^{38}$ Ibid.

${ }^{39}$ Stalker ['Stalker’], dir. by Andrei Tarkovskii (Mosfil’m, 1979) [English subtitles].
} 
significantly different paths. In Lem's original text, the scientists run tests on the creatures, revealing that the phantoms are not atomic-based structures, but instead are composed of neutrino-based matter. Through the realisation that the psicreatures are not strictly alive, the scientists ease some of their epistemological anguish in dealing with their presence on the space station. In the film, however, Tarkovskii injects more life into the phantoms as they become more than mechanical copies of their past selves. The materialised ghost from Kris' memory, his dead wife Hari, becomes not only "real", but almost more real than the living characters, because she retains the ability to love and express true emotion. In reaction to this paradox, Kris exclaims: 'But what does it matter if you are clearer to me than all the scientific truths which have existed in this world?' ${ }^{40}$ Hereafter, the crux of the film is Kris coming to terms with this non-sensical truth at the expense of science and rationalism. This quandary gives Tarkovskii further ammunition for his central conflict between the two separate worlds, the external and the internal. Because the phantoms defy reality, knowledge from the external world is brought into question and is eventually superseded by memory and subjectivity that come from within. By putting more certainty in these internal truths, Tarkovskii is able to reset the balance of inner versus outer knowledge in the original novel.

Because of these changes, Lem was highly critical of Tarkovskii's adaptation. He stated in a 1979 interview that the director created a

[...] moral drama par excellence, which in no way relates to the problems of cognizance and its extremes. For Tarkovskii the most important facet was Kris's problem of "guilt and punishment", just as in a Dostoievskii book. ${ }^{41}$

This demonstrates Lem's preoccupation with 'problems of cognizance' as opposed to Tarkovskii's emphasis on moral issues. This contrast is, however, complicated by the fact that epistemology and ethics are, to some extent, interdependent and overlap. The way that we perceive morality is dependent on what we know, or what we think we know, about the human condition. The opposite is also true as we prioritise

\footnotetext{
${ }^{40}$ Solaris, Tarkovskii.

${ }^{41}$ Stanisław Lem, quoted in Jeremy Robinson, The Sacred Cinema of Andrei Tarkovsky (Maidstone: Crescent Moon, 2007), p. 392. Lem's view is corroborated by Tarkovskii himself in an interview, first with Ian Christie in 1981 and again with Laurence Cossé in 1986. See Gianvito, Interviews, p. 66, p. 167.
}

(c) School of Slavonic and East European Studies, University College London, 2014. 
different forms of knowledge based on what we think constitutes moral behaviour. When Lem and Tarkovskii pose their questions regarding knowledge they undoubtedly tip the scales balancing ethics and epistemology to suit their interests. In his analysis, Nariman Skakov recognises this balancing act, creating the analogy: 'The epistemological questions which shape the text of the novel are transmuted into a quest to regain self-knowledge through the prism of ethical judgement' ${ }^{42}$ Therefore, for Tarkovskii's characters, the knowledge barrier is more reflective, putting a focus on internal truths that are forever encumbered with ethical concerns.

Whilst Tarkovskii's second "science fiction" film, Stalker, constitutes the focus of the next section of this paper, it is important to recognise here the differences between the representation of knowledge in the original novels he adapted, Solaris and Roadside Picnic. This topic is considered by George Slusser in his article, 'Structures of Apprehension: Lem, Heinlein, and the Strugatskiis' (1989). ${ }^{43}$ Slusser, who does not make reference to Tarkovskii's adaptations, senses a 'very different epistemological feel' between Solaris and Roadside Picnic, stemming mainly from their narrative structure and setting. ${ }^{44}$ He claims that Solaris is, in essence, a 'space epic' in which scientists travel to the distant cosmos and are thereby 'physically annexed by acts of exploration'. ${ }^{45}$ In other words, the protagonists are literally placed at the frontiers of human knowledge. By contrast, Roadside Picnic functions more as an "it-came-from-outer-space" tale akin to The War of the Worlds (1898) ${ }^{46}$ in which the scientists are forced less to act than react to the alien visitation. ${ }^{47}$ The key difference for Slusser is the degree of activity or passivity in the quest for knowledge in the two novels. With Solaris, Lem is more interested in the distress caused to the scientists when they reach the limit of truth in human understanding. In Roadside Picnic, the Strugatskii brothers are less concerned with the end of the journey (the truth) as they are with the journey itself. The variance between the novels helps to

\footnotetext{
${ }^{42}$ Nariman Skakov, The Cinema of Tarkovsky: Labyrinths of Space and Time (London: I.B. Taurus, 2012), p. 99 (hereafter: 'Skakov, Labyrinths').

${ }^{43}$ George E. Slusser, 'Structures of Apprehension: Lem, Heinlein, and the Strugatskys', Science Fiction Studies, 16:1 (Mar., 1989), pp. 1-37 (hereafter: 'Slusser').

${ }^{44}$ Slusser, p. 2.

${ }^{45}$ Ibid.

${ }^{46}$ Herbert George Wells, War of the Worlds (Plain Label Books, 1898).

${ }^{47}$ Slusser., p. 6.
} 
explain some of the differences between the two films in question. Regardless of how far Tarkovskii strayed from the original content, the novels undoubtedly influenced the representation of knowledge in the films. Indeed, Tarkovskii was openly critical of Solaris, labelling it his weakest film as he was unable to fully rework the core philosophy of Lem's novel and to shake the restrictions of the genre. ${ }^{48}$ By using Roadside Picnic, and therefore also the Strugatskii brothers' philosophy of knowledge, as raw material for his later film, Tarkovskii was able to exercise his philosophy on knowledge more freely.

In his recent book, Skakov reaches the conclusion that Tarkovskii's dealings with science fiction were ultimately unsuccessful as he 'tried to reconcile the irreconcilable: he is desperate to humanise the fantastic genre and to undermine the rigid opposition between the real and the hallucinatory' ${ }^{49}$ While he may not have been wholly successful in his attempt to subvert the genre to his means, the two films are, to a greater or lesser degree, representative of his humanistic ideology. Close reading of Solaris and Stalker shows that Tarkovskii was faithful to his core ideas about knowledge, although his ideology is noticeably more pronounced in the second half of his career. There are several contributing factors that explain this. Firstly, the differences of epistemology between the original novels, as already highlighted by Slusser, which inevitably filtered down into Tarkovskii's films, regardless of how far they strayed from the written content. Secondly, pressures from Goskino and Lem to satisfy the conventions of the ever-popular science fiction genre in the early 1970s prevented Tarkovskii from freely exercising his views on knowledge in Solaris. Finally, and of greatest significance, there was a conscious shift in the second half of Tarkovskii's career into the spiritual, quasi-religious realms of Dostoevskii that influenced the way he personified spiritual truth within certain characters and gave him the vocabulary to plainly spell out his ideas about truth and knowledge.

\footnotetext{
${ }^{48}$ Gianvito, Interviews, p. 173.

${ }^{49}$ Skakov, Labyrinths, p. 98.
} 


\section{Truth in Art}

\section{'The Two Cultures': Art and Science}

As demonstrated in the first section of this paper, Tarkovskii's ideas about scientific truth are, at times, clearly pronounced, while speculation on his conception of aesthetic truth is naturally the more deceptive element of his epistemology. In Sculpting in Time, Tarkovskii works to glorify aesthetic truth, describing it as 'a symbol of the universe' which is 'hidden from us in our positivistic, pragmatic activities'. ${ }^{50}$ He goes on to explain that 'art, like science, is a means of assimilating the world, an instrument for knowing it in the course of man's journey towards what is called "absolute truth"'.51 Within this list of highly romanticised images of art, which continues for several pages, it is possible to discern two constants. The first is that aesthetic truth is limitless. Unlike the relative finitude of science, the possibilities of art have no boundaries. This is true for both artistic inspiration and interpretation. Tarkovskii, returning to the staircase metaphor, proposes that if cold, positivistic, scientific cognition of the world is like the ascent of a staircase, its artistic counterpoint suggests an endless system of spheres, each one perfect and contained within itself'.52 The second constant is that true art can only be understood subjectively. Tarkovskii often belittled the objective, universal laws of science, in favour of subjectively experienced art represented in his metaphor by a 'sphere' that is 'perfect and contained within itself'. 53

By representing the so-called divide between art and science in a reductive, diametric way, Tarkovskii's work is reminiscent of Dostoevskii's confrontation with Chernyshevskii and the rationalists in the mid-nineteenth century. In his essay 'The Aesthetic Relations of Art to Reality', Chernyshevskii asserted that art was merely a mechanical reproduction of reality and could therefore be interpreted in a logical way much like the sciences. ${ }^{54}$ Dostoevskii strongly disagreed with such utilitarian

\footnotetext{
50 Tarkovskii, Sculpting in Time, p. 37.

51 Ibid.

52 Ibid., p. 39.

53 Ibid.

${ }^{54}$ Nicholas Chernyshevskii, 'The Aesthetic Relations of Art to Reality', Selected Philosophical Essays, (Moscow: Foreign Languages Publishing House, 1953).
}

(c) School of Slavonic and East European Studies, University College London, 2014. 
views on art and aesthetic beauty, a sentiment that is echoed by Tarkovskii in the following passage:

Art does not think logically, or formulate a logic of behaviour; it expresses its own postulate of faith. If in science it is possible to substantiate the truth in one's case and prove it logically to one's opponents, in art it is impossible to convince anyone that you are right if the created images have left him cold. ${ }^{55}$

To say that art is infinite and subjective is, of course, highly clichéd, yet Tarkovskii repeatedly returns to these two factors to defend his notion of aesthetic truth. Because of the apparent finite/infinite and objective/subjective qualities that separate science and art, Tarkovskii perceives a divide between the two specialities that leaves little room for overlap. This unwavering position associates him with the views of Dostoevskii and at the same distances him from many of his contemporaries in film and art. Many of the great Soviet artists, especially in the fields of cinema and science fiction literature, had close affinities with science, including Dziga Vertov, Sergei Eisenstein, Ivan Yefremov and Mikhail Bulgakov among others. Stanisław Lem, a medical student and scientific researcher, and Boris Strugatskii, an astronomer and computer engineer, show great respect for scientific thinking in their novels. They do not perceive the realms of art and science to be poles apart, but consider them to be complimentary. In this respect they hark back to the words of Chekhov who famously stated in a letter to A.S. Suvorin:

I feel more confident and more satisfied when I reflect that I have two professions and not one. Medicine is my lawful wife and literature is my mistress. When I get tired of one I spend the night with the other. Though it's disorderly it's not so dull, and besides, neither really loses anything, through my infidelity. ${ }^{56}$

Because of their 'infidelity', Lem and the Strugatskii brothers occupy a critically different perspective to Tarkovskii on the role of truth in art and science. Recognition

\footnotetext{
55 Tarkovskii, Sculpting in Time, p. 41.

${ }^{56}$ Anton Chekhov, letter dated 11 September 1888. See 'Letters of Anton Chekhov to his Family and Friends', Pennsylvania State University (2008), <http://www2.hn.psu.edu/faculty/jmanis/checkov/Chekhov_Letters.pdf> [accessed 15 November 2013].
}

(c) School of Slavonic and East European Studies, University College London, 2014. 
of this is important because it has great implications for the way they present the different strands of knowledge in their respective works. Because Tarkovskii perceives a fundamental imbalance between art and science, he is more readily able to dissect the different forms of truth and present them in opposing categories. For Lem and the Strugatskii brothers, the relationship between scientific truths and what Tarkovskii labels 'aesthetic' or 'spiritual' truths is more complex. Much of this complexity boils down to the interaction of imagination and reality in relation to truth, which adds yet another paradigm with which to inspect the differences between Tarkovskii and the respective authors.

\section{Fluid Worlds: Imagination and Reality}

In an article published in the Science Fiction Studies journal, David Field discusses Lem's Solaris and Nabokov's Ada in relation to the authors' views on the interaction between art and science. ${ }^{57}$ Field argues that, for Lem and Nabokov, the two specialities are inherently linked because they have dynamic ties to both imagination and reality. He explains that 'without its imaginative component, science would lose the driving force of creative observation and theory, and without a subtle and precise sense of external reality, art would become abstract, detached and even insane'. ${ }^{58}$ In other words, science needs the imaginative aspect of art for new hypotheses; art needs the critical aspect of science to 'awaken the imagination into activity' ${ }^{59}$ This suggests that there is a greater degree of cross-fertilisation between the rationality of the scientist and the irrationality of the artist than Tarkovskii and others profess. Field concludes that because Lem and Nabokov both acknowledge these 'fluid boundaries' between imagination and reality, and thereby science and art, they place greater emphasis on the 'theoretical issues concerning the nature of knowledge' in their novels. ${ }^{60}$ The consequence of this is that Lem and Nabokov, much like the Strugatskii brothers, create worlds in which there exists an incestuous relationship between scientific and aesthetic truths.

\footnotetext{
57 David Field, 'Fluid Worlds: Lem's "Solaris" and Nabokov's "Ada", Science Fiction Studies, 13:3 (Nov., 1986), pp. 329-44 (p. 331) (hereafter: 'Field, 'Fluid Worlds").

${ }^{58}$ Ibid., p. 329.

${ }^{59}$ Sheldon Richmond, 'The Interaction of Art and Science', Leonardo, 17:2 (1984), pp. 81-86 (p. 81 ).

${ }^{60}$ Ibid.
} 
What Field's article does not attempt is a comparison with other Soviet artists of opposing beliefs. Tarkovskii would be an ideal candidate for this as he considers artistic imagination and scientific hypothesis to be essentially separate entities. Tarkovskii asserts that 'even though a scientific discovery may seem to be the result of inspiration, the inspiration of the scientist has nothing in common with that of the poet'. ${ }^{61}$ For the director, artistic imagination is triggered by a deep, subjective knowledge that is informed by reality in a purely illogical way. In certain respects, this is influenced by his central conflict between two separate worlds, highlighted in the introduction: the external and the internal. To put it simply, for Tarkovskii, scientific truths are limited to a formulaic understanding of the 'real' external world and aesthetic truths are processed internally from individual imagination.

The concept of imagination versus reality marks a key philosophical idea that separates Tarkovskii from both Lem and the Strugatskii brothers. Again, this can be observed in the changes made in the adaptation process. Tarkovskii chose to omit key passages from both Solaris and Stalker that discuss the scientific process in favour of linking film with the wider arts. In the novel Solaris, Kris reads multiple volumes on the history of 'Soliaristics', a branch of science dedicated to understanding the planet-ocean Solaris which has developed over centuries and been divided into a multitude of different academic fields. These different fields are so specialised that a 'Soliarist-cybernetician had difficulty in making himself understood to a Soliaristsymmetriadologist' ${ }^{62}$ With this, Lem is undoubtedly alluding to the divisiveness of science and academia. Similarly, Roadside Picnic features a meta-literary element, as illustrated by the scientist Pilman reading a book called History of the Visitation, which documents the scientific study of the Zone.63 In both cases, the nature of scientific thought is presented in such a way that new theories stem from the scientist's imagination. The way that they conceptualise the alien-planet and create hypotheses is dependent on the individual scientist's personality and subjectivity. Tarkovskii, by contrast de-humanises all aspects of science, allowing only selected characters the capacity for real imagination.

\footnotetext{
${ }^{61}$ Tarkovskii, Sculpting in Time, p. 40.

${ }^{62}$ Lem, Solaris, p. 26.

${ }^{63}$ Strugatskii, Roadside Picnic, p. 34.
}

(c) School of Slavonic and East European Studies, University College London, 2014. 
It is of course conceivable that these 'meta-literary' aspects of the books would be too difficult to fully replicate in film. Nonetheless, this omission is consistent with Tarkovskii's philosophy. In his adaptation, Tarkovskii replaces these scientific documents with works of art. This is most evident in the reworking of the library sequence in Solaris which sees the camera explore the room to reveal a collection of artistic artefacts brought from Earth: Pieter Bruegel's vista The Hunters in the Snow (1565), Dostoevskii's Crime and Punishment (1866), Miguel de Cervantes' Don Quixote (1605-1615), and a bust of Socrates. The fact that Tarkovskii stages this artistic revival in the library is important because it is the only room in the space station that does not have windows looking out onto the planet Solaris. He therefore tried, as far as it was possible, to make this a terrestrial experience for the characters, removing any futuristic technology and adding art classics and objects of high modernity.

Herein lies the final way that Tarkovskii differentiates between art and science: time. One of the most distinguishable elements of Tarkovskii's films is that they do not follow unidirectional, historical time. Instead, Tarkovskii presents time as a malleable object, calling his artistic method 'sculpting in time'. His films do not have a defined tense, but above all, they look toward the past as his characters live in dreams, memories, and fantasies, creating their own personal, subjective time. Tarkovskii shows great respect for the past, as demonstrated by his use of classical art and engagement with antiquated practices such as holy foolishness (iurodstvo). ${ }^{64}$ In Tarkovskii's eyes, science is orientated towards an end-point in the future. The scientific process is one that works to gradually amass objective facts until it has brought the entire human condition under complete understanding. It presumes that the physical laws of the Universe are already given and are simply waiting to be discovered, recalling the finite/infinite divide between the scientific and aesthetic truth. Tarkovskii ultimately sees science as having an end-point, creating for itself a

\footnotetext{
${ }^{64}$ For example, the main character in Tarkovskii's Stalker is a half-mad, half-blessed fool-in-Christ type of character, who alone bears a special sensibility for hidden truths beyond the material appearance of things. See: Vida T. Johnson, 'Laughter beyond the mirror: Humor and satire in the cinema of Andrei Tarkovsky', Inside Soviet Film Satire, ed. by Andrew Horton (Cambridge: Cambridge University Press, 2005), pp. 98-104 (p. 102).
} 
'knowledge barrier' that is self-limiting. Art, by contrast is timeless and subjective which makes it incomparable yet infinitely superior to scientific knowledge.

Tarkovskii's belief in the redemptive power of art is not especially original or indeed surprising. What distinguishes Tarkovskii from his contemporaries, however, is his conviction that there is a fundamental imbalance between art and science. He, at times, is prone to representing aesthetic truth and scientific truth as two separate entities, each competing for a stake on knowledge and thereby dividing humanity. His final remarks in Sculpting in Time succinctly convey this assertion:

Seeing ourselves [the human race] as the protagonists of science, and in order to make our scientific objectivity more convincing, we have split the one indivisible human process down the middle, thereby revealing a solitary, but clearly visible spring, which we declare to be the prime cause of everything, and use it not only to explain the mistakes of the past but also draws up our blueprint for the future. ${ }^{65}$

His contemporaries are not able to make such steadfast judgements about the relationship between art and science, Lem and the Strugatskii brothers being prime examples. As Field discusses in his article, the science fiction authors created 'fluid worlds' in which science and art co-exist and germinate from the equally fluid concepts of imagination and reality. The authors show great respect for the findings of modern science in their novels and this undoubtedly has an effect on the epistemological feel of the text. Tarkovskii, by contrast, denies the imaginative aspect of scientific thought, often restricting science to objective statements about the external world.

\section{Conclusion}

This article has demonstrated that the struggle for truth is at the core of Tarkovskii's art and philosophy. Having analysed both films in detail, it is possible to detect a basic principle by which Tarkovskii represents knowledge. First, he exposes a rift

\footnotetext{
${ }^{65}$ Tarkovskii, Sculpting in Time, p. 240.
}

(C) School of Slavonic and East European Studies, University College London, 2014. 
between what he perceives as opposing forms of knowledge: scientific and aesthetic/spiritual. These two forms are supported by a number of secondary oppositions that help distinguish them: objective/subjective, external/internal, finite/infinite and real/imaginative. These qualities are then personified by individual characters who enact them in an uncompromising fashion. This is most transparent in Stalker where the three protagonists are assigned a specific profession that conveys a certain truth and creates the anonymity of the characters under archetypal titles of 'Scientist', 'Writer', and 'Stalker'. Equipped with their specific form of knowledge, they engage in an epistemological debate that is grounded in a quest narrative. The conditions are such that the different forms of knowledge do not compete on equal terms but work to support Tarkovskii's preconceived ideas about the nature of truth. The result is an epistemic hierarchy in which some truths are in a way more true than others.

In Tarkovskii's world, the dehumanised, objective knowledge of science is always superseded by his preferred aesthetic truths. Analysis has shown that Tarkovskii slants his core questions of epistemology in such a way as to invalidate scientific truths before they enter the debate. In fact, Tarkovskii's questioning of science in the dialogue of Stalker is so blatant that it has received criticism for being overly explicit in exposing the film's basic ideology. ${ }^{66}$ Indeed, in both films, his aspirations for a higher truth are somewhat clouded by the fact that there is an overriding focus on perils of scientific knowledge. Therefore, because he develops his argument through negation, he is at risk of representing his preferred truths as distant abstractions.

For Tarkovskii, humanity will find its salvation not in the medical and technological advances of science but in artistic expression. The second part of this paper, 'Truth in Art', demonstrated that a romanticised notion of an infinite aesthetic truth sits comfortably at the top of Tarkovskii's hierarchy of knowledge. Identifying this aesthetic truth as the focal point of Tarkovskii's ideas about knowledge is not a difficult task. He is explicit in interviews and his films that he sees art and spirituality as the gateway to absolute truth. However, unlike his view of scientific

\footnotetext{
${ }^{66}$ Johnson and Petrie, A Visual Fugue, p. 146.
} 
truth, which is unashamedly transparent, his aesthetic truth is, necessarily, the most abstract element of his epistemology. Tarkovskii's own cinematic aesthetic is based on the idea that art cannot be understood in any kind of rational way. His famous lecture at St James's Church, Piccadilly, in 1984 strayed from its original topic of the 'apocalypse' to reaffirm his belief that '[t]he moment a viewer understands, deciphers, all is over, finished: the illusion of the infinite becomes banality, a commonplace truism' ${ }^{67}$ For Tarkovskii, therefore, aesthetic truth can only be found within the individual and any attempt to corner it is counter-productive.

Ultimately, Tarkovskii cannot rationally defeat his enemies. There is no viable way to compare scientific and aesthetic "truths". Only scientific truth can be validated in any kind of logical way. Tarkovskii's intuition that absolute truth is to be found in art may well be accurate, yet it cannot be tested. This conundrum recalls the most basic question of epistemology: What is knowledge? Many would consider faith, spirituality, and art to be outside or above knowledge. Because Tarkovskii chooses to assess them as comparable items he oversimplifies the debate and actually sets it up in a way that is impossible for him to succeed. In the end, the real question that Tarkovskii presents the viewer with is: What is not knowledge? He answers his own question definitively: the scientific. While he prided himself on making films which ask open-ended philosophical and theological questions, with Solaris and Stalker he presents the viewer with a one-sided debate. However, while Tarkovskii's attempt to distinguish truth from falsehood is flawed, insight into this can help broaden our understanding of his life and works. His epistemology, with its inherent paradoxes and contradictions, inevitably filters down into his aesthetic and his films. Tarkovskii would have argued, of course, that it is precisely in their illogicality that his films find beauty and truth, but this argument itself could ultimately be perceived as self-defeating.

This work is licensed under the Creative Commons Attribution-Non-commercial-Share-alike 2.0 UK: England \& Wales License. This license allows for redistribution and alteration, commercial and non-commercial, as long as credit is given to the author. To view a full copy of this license, visit: http://creativecommons.org/licenses/ or send a letter to Creative Commons, 444 Castro Street, Suite 900, Mountain View.

\footnotetext{
${ }^{67}$ Tarkovskii quoted in ibid., p. 38.
} 